\title{
Regional Art Studies in Modern Russia (Introductory Article)
}

\author{
Natalia P. Koptseva* \\ Siberian Federal University \\ Krasnoyarsk, Russian Federation
}

Received 10.10.2021, received in revised form 10.12.2021, accepted 18.01.2022

\begin{abstract}
The introductory article reveals the principles of forming a science direction, dedicated to the theory and history of arts, for the journal of the Siberian Federal University «Humanities \& Social Sciences». To analyze the topical problems of regional scientific schools of contemporary Russian art history, several principles were chosen: geographical (when studies are presented by regions where the corresponding scientific schools are developing), historical (in accordance with the problems characteristic of one or another significant era in the history of world and domestic art), conceptual (in accordance with the basic ideas, theories, concepts that are shared by the authors), thematic (uniting scientists dealing with similar art history issues).

The main approaches of the authors, the topics of their articles, art history ideas and theories that they develop are presented. At this point the schools of Russian art history are associated with the cities of Moscow, St. Petersburg, Chelyabinsk and Krasnoyarsk.
\end{abstract}

Keywords: art history, regions, Russia, scientific schools, work of art, music, fine arts.

Acknowledgements: The research was funded by RFBR, Krasnoyarsk Territory and Krasnoyarsk Regional Fund of Science, project number 20-49-240001.

Research area: theory and history of culture, art; types of art (fine arts, arts and crafts, musical art).

(C) Siberian Federal University. All rights reserved

* Corresponding author E-mail address: nkoptseva@sfu-kras.ru ORCID: 0000-0003-3910-7991 


\title{
Региональные искусствоведческие исследования в современной России (вступительная статья)
}

\author{
Н.П. Копцева \\ Сибирский федеральный университет \\ Российская Федерация, Красноярск
}

\begin{abstract}
Аннотация. Здесь раскрываются принципы формирования тематических выпусков журнала Сибирского федерального университета «Гуманитарные науки», посвященных теории и истории искусств. Для анализа актуальных проблем региональных научных школ современного российского искусствоведения были выбраны несколько принципов: географический (когда исследования представлены по регионам, где развиваются соответствующие научные школы), исторический (в соответствии с проблематикой, характерной для той или иной значимой эпохи в истории мирового и отечественного искусства), концептуальный (в соответствии с базовыми идеями, теориями, концепциями, которые разделяются авторами), тематический (объединяющий ученых, занимающихся схожей искусствоведческой проблематикой).

Показаны основные подходы авторов, тематика их статей, искусствоведческие идеи и теории, которые они развивают. Представленные школы отечественного искусствоведения связаны с городами Москва, Санкт-Петербург, Челябинск и Красноярск.
\end{abstract}

Ключевые слова: искусствоведение, регионы, Россия, научные школы, произведение искусства, музыка, изобразительное искусство.

Благодарности: исследование выполнено при финансовой поддержке РФФИ, Правительства Красноярского края и Красноярского краевого фонда науки в рамках научного проекта № 20-49-240001.

Научная специальность: 5.10.1 - теория и история культуры, искусства, 5.10.3 виды искусства (изобразительное искусство, декоративно-прикладное искусство, музыкальное искусство).

Уважаемые читатели, коллеги, представляем вашему вниманию тематическое направление научного журнала Сибирского федерального университета, посвященное региональным исследованиям в области теории и истории искусств. Мы предлагаем своеобразный научный отчет наших авторов, чьи исследования посвящены актуальным проблемам мирового и отечественного искусства. В искусствоведческих выпусках встретились ученые из Москвы, СанктПетербурга, Красноярска, Челябинска. Большое количество материалов посвящено российским исследованиям музыкального искусства, классического и современного изобразительного искусства, декоративноприкладного искусства коренных малочисленных народов Севера, Сибири и Дальнего Востока, художественному образованию в Сибири, изобразительному искусству древней Сибири. Спектр искусствоведческих проблем значителен. Историю искусства дополняют работы в области теории и философии искусства.

Хотелось бы отметить, что здесь представлены практически все значимые эпохи 
в истории искусства. Статья Ксении Дегтяренко, Юлии Менжуренко, Дарьи Пчелкиной и Анны Шпак (Сибирский федеральный университет, г. Красноярск) «Древние художественные произведения Центральной Сибири» посвящена выделению среди ряда археологических памятников тех вещей, которые можно атрибутировать как произведения искусства. Речь идет о самых первых художественных произведениях в истории человечества. Для атрибуции применены принципы теории культуры как идеалообразования Д.В. Пивоварова (Pivovarov, 2013, Kistova, 2020, Koptseva, et o., 2018), а также концепция произведения искусства как художественного образа, который обладает искусственностью, искусностью и искусом, изложенная в работах В.И. Жуковского и Н.П. Копцевой (Sitnikova, \& Zhukovskaia, 2015, Zhukovskij \& Koptseva, 2004).

Очень близки к архаике, но при этом удивительно актуальны художественные произведения северных и сибирских народов, которые анализирует Наталья Середкина в работе «Изобразительное искусство в художественной культуре коренных малочисленных народов Севера, Сибири и Дальнего Востока РФ» (Сибирский федеральный университет, г. Красноярск). К этой же тематике принадлежит и работа Ксении Резниковой, Натальи Копцевой, Юлии Квашниной и соавторов «Культурная динамика коренных малочисленных народов Севера Красноярского края в живописных и графических произведениях». Данные исследования проводятся в Сибирском федеральном университете более 10 лет, их основу составляют полевые исследования в местах традиционного проживания коренных народов Севера и Сибири (Reznikova, et o., 2019, Seredkina, 2014, Sitnikova, et o., 2018).

Древнерусское искусство представлено в работах наших коллег из Научноисследовательского Южно-Уральского государственного университета (г. Челябинск) - Семена Ворошина «Отражение духовного мира Никиты Григорьевича Строганова в церковном искусстве», Натальи Парфентьевой и Николая Парфентье- ва «К проблеме атрибуции цикла стихир «Отче преблаженне в честь митрополита всея Руси Петра...». Новое время в истории искусства ярко отражено в работе Екатерины Сертаковой, Марии Колесник и Натальи Лещинской ««Героизм» и «трагизм» в живописи неоклассицизма XVIII века (на примере анализа произведений Ж.-Л. Давида».

Искусствовед Нина Геташвили (Российская академия живописи, ваяния и зодчества Ильи Глазунова, г. Москва) в статье «Вечные образы Античности и искусство второй половины XX - начала XXI века: опыт функционального анализа» внимательно анализирует яркое современное художественное явление, связанное с рецепцией античности в искусстве постмодерна европейских и российских художников, раскрывая культурные основы этого феномена.

Новейшие тенденции в искусстве показаны в статье Александры Ситниковой, Юлии Замараевой, Тихона Ермакова и соавторов «Особенности развития партиципаторного искусства в городе Красноярске (Российская Федерация) в начале XXI века» (Сибирский федеральный университет, г. Красноярск). Речь идет о произведениях, которые ориентированы на активное взаимодействие со зрителями, слушателями и нацелены на преобразование их художественного мировосприятия.

Несмотря на огромную популярность в медийной среде творчества красноярского художника Василия Слонова, искусствоведческий анализ его произедений чуть ли не впервые дан в работе Александры Ситниковой и соавторов (Сибирский федеральный университет, г. Красноярск) «Творчество красноярского художника Василия Слонова». Именно хорошая теоретическая база позволяет выделить основные художественные идеи картин этого художника, определить их значимость и актуальность для современных зрителей.

Большой раздел в номере связан с музыковедческими исследованиями. Так, в статье санкт-петербургского музыковеда Александры Косых (СанктПетербургская государственная консер- 
ватория им. Н.А. Римского-Корсакова, г. Санкт-Петербург) «Псалом духоборцев Даватехии «Узрех много народу» как характерный пример жанра» анализируются особенности христианской музыкальной культуры духоборцев, религиозного сообщества, которое можно отнести к русским протестантам. Евгения Редькова (СанктПетербургская государственная консерватория им. Н.А. Римского-Корсакова, г. Санкт-Петербург) в статье «Понятие «жанр» в научном исследовании Ф. А. Рубцова» вводит в отечественное музыковедение важные теоретико-музыковедческие открытия ленинградского композитора, музыковеда, профессора консерватории Феодосия Антоновича Рубцова (1904-1986).

Значительное место в выпуске занимают работы искусствоведов и музыковедов Сибирского государственного института искусств им. Д. Хворостовского: Марины Москалюк и Ильи Царинного «Полихромия в современной российской скульптуре», Светланы Войткевич и Веры Барановой «Образ Парфена Рогожина в опере М. Вайнберга и А. Медведева», Натальи Найко «Элементы программности в инструментальных сочинениях позднего периода Олега Меремкулова...», Марии Холодовой «Балет Г.И. Банщикова...», Марии Чихачевой и соавторов «Художественная школа Красноярского края...», Лилии Строй и Евгении Царевой «Музыкальное образование
Енисейской губернии конца XIX - начала XX века», Альфии Шаяхметовой «Философское осмысление музыки и поэзии в суфизме», Светланы Яковлевой и Юлии Колпаковой «Западноевропейская гравюра в сибирской коллекции...».

Теоретические исследования дополняет работа Сергея Соковикова (г. Челябинск, Челябинский государственный институт культуры и искусств) «Взаимодействие балета и литературы: проблемы перевода». Эта статья примыкает к исследованиям красноярских музыковедов и дает возможность по-новому понять взаимодействие различных видов искусств в системе художественной культуры.

Таким образом, на страницах журнала встретились представители различных научных искусствоведческих школ. Круг их научных интересов чрезвычайно разнообразен и удивительно актуален. Российское региональное искусствоведение находится «в хорошей форме», его концептуальный потенциал несомненен. Показательно, что объем материалов позволил сформировать сразу два тематических выпуска - 15(1) и 15(6). Мы надеемся, что в будущем сможем не раз представить новые результаты наших коллег, и на страницах издания будут разворачиваться современные дискуссии по наиболее важным проблемам отечественной теории и истории искусства.

\section{Список литературы / References}

Kistova, A.V. (2020). Sinteticheskaya model' kul'tury i kul'turnye praktiki [Synthetic model of culture and cultural practices], In Sibirskij antropologicheskij zhurnal [Siberian Anthropological Journal], 2 (6), $111-121$.

Koptseva, N., Reznikova, K.V., Razumovskaya, V.A. (2018). The construction of cultural and religious identities in the temple architecture, In Journal of Siberian Federal University - Humanities and Social Sciences,11 (7), 1021-1082.

Pivovarov, D.V. (2013). Kul'tura i religiya: sakralizatsiya bazovykh idealov [Culture and religion: sacralization of basic ideals]. Yekaterinburg.

Reznikova, K.V., Pimenova, N.N., Kistova, A.V., et other (2019). Ethnocultural Space of Krasnoyarsk Krai: The Current State, in Journal of Siberian Federal University. Humanities and Social Sciences, 12(8), $1552-1567$.

Semenova, A.A., Gerasimova, A.A. (2013). Osobennosti tvorcheskogo metoda Sergeya Anufrieva [Features of the creative method of Sergei Anufriev], in Sovremennye problemy nauki i obrazovaniya Modern problems of science and education], 2, 542. 
Seredkina, N.N. (2014). Revisiting Methodological Principles of Cultural-semiotic Approach in Studying Art of Indigenous Peoples of The North, Siberia and The Far East, In Journal of Siberian Federal University. Humanities and Social Sciences, 7(8), 1342-1357.

Sitnikova, A.A., Pimenova, N.N., Filko, A.I. (2018). Pedagogical Approaches to Teaching and Adaptation of Indigenous Minority Peoples of The North in Higher Educational Institutions, in Novosibirsk State Pedagogical University Bulletin, 8(4), 26-45.

Sitnikova, A.A., \& Zhukovskaia, L.N. (2015). Visualization of the essence (about the creative work of the artist Vladimir Zhukovsky), In Journal of Siberian Federal University. Humanities and Social Sciences, 8(1), 137-144.

Zhukovskij, V.I., Koptseva, N.P. (2004). Propozicii teorii izobrazitel'nogo iskusstva [Propositions of the theory of fine arts]. Krasnoyarsk, Krasnoyarskij gosudarstvennyj universitet. 